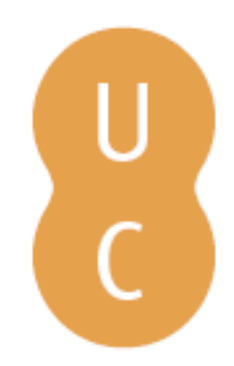

\title{
nommalina
}

\section{O vinho e os vinhos: usos e virtudes de um dom dos deuses nas Enarrationes de Amato Lusitano}

\author{
Autor(es): $\quad$ Reis, Telmo Corujo dos \\ Publicado por: UA Editora - Universidade de Aveiro; Imprensa da Universidade de \\ URL \\ persistente: URI:http://hdl.handle.net/10316.2/35706 \\ DOI: $\quad$ DOI:http://dx.doi.org/10.14195/978-989-26-0941-6_20 \\ Accessed : $\quad$ 17-Jan-2018 09:13:07
}

A navegação consulta e descarregamento dos títulos inseridos nas Bibliotecas Digitais UC Digitalis, UC Pombalina e UC Impactum, pressupõem a aceitação plena e sem reservas dos Termos e Condições de Uso destas Bibliotecas Digitais, disponíveis em https://digitalis.uc.pt/pt-pt/termos.

Conforme exposto nos referidos Termos e Condições de Uso, o descarregamento de títulos de acesso restrito requer uma licença válida de autorização devendo o utilizador aceder ao(s) documento(s) a partir de um endereço de IP da instituição detentora da supramencionada licença.

Ao utilizador é apenas permitido o descarregamento para uso pessoal, pelo que o emprego do(s) título(s) descarregado(s) para outro fim, designadamente comercial, carece de autorização do respetivo autor ou editor da obra.

Na medida em que todas as obras da UC Digitalis se encontram protegidas pelo Código do Direito de Autor e Direitos Conexos e demais legislação aplicável, toda a cópia, parcial ou total, deste documento, nos casos em que é legalmente admitida, deverá conter ou fazer-se acompanhar por este aviso.

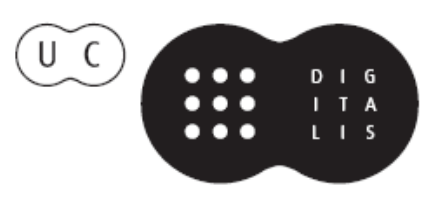




\section{HUMANISMO E CIÊNCIA Antiguidade e Renascimento}

António Manuel Lopes Andrade

Carlos de Miguel Mora

João Manuel Nunes Torrão
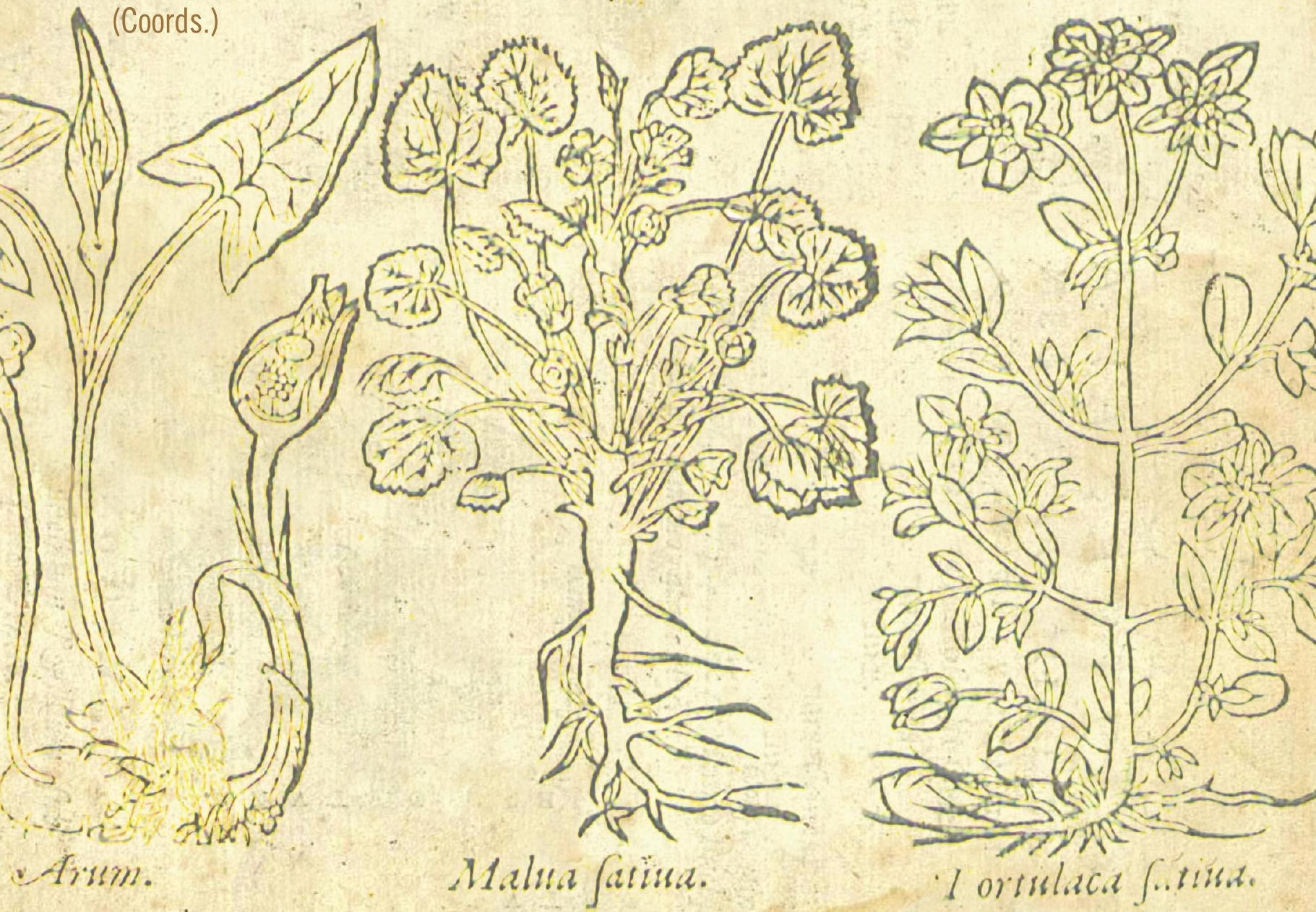

Aveiro I Coimbra I São Paulo 2015

UA Editora - Universidade de Aveiro I Imprensa da Universidade de Coimbra I Annablume 
Este volume resulta de várias iniciativas desenvolvidas no âmbito do projecto de I\&D "Dioscórides e o Humanismo Português: os Comentários de Amato Lusitano" (http://amatolusitano.web.ua.pt), recoIhendo contribuições de mais de duas dezenas de colaboradores, tanto de membros da equipa como de outros investigadores nacionais e estrangeiros. Entre os eventos que estiveram na origem deste livro destacam-se as três edições do Ciclo de Conferências promovido pelo projecto, realizadas entre 2010 e 2013, e sobretudo o Colóquio Internacional "Dioscórides e o Humanismo Português: os Comentários de Amato Lusitano", que decorreu no Departamento de Línguas e Culturas da Universidade de Aveiro, nos dias 21 e 22 de Novembro de 2013.

0 objectivo principal do projecto é a edição e tradução para português dos dois livros que Amato Lusitano dedicou ao comentário do tratado grego De materia medica de Dioscórides, ou seja, o Index Dioscoridis (Antuérpia, 1536) e as In Dioscoridlis Anazarbei de medica materia libros quinque... enarrationes (Veneza, 1553), estando contemplada, também, a tradução de mais duas obras directamente correlacionadas com os livros do médico português: a montante, a do próprio tratado grego de Dioscórides; a jusante, a do livro intitulado Apologia adversus Amathum Lusitanum (Veneza, 1558) de Pietro Andrea Mattioli.

OBRA PUBLICADA COM A COORDENAÇÃO

CIENTÍFICA DE:

Centro de Línguas, Literaturas e Culturas da Universidade de Aveiro

Centro de Estudos Clássicos e Humanísticos da Universidade de Coimbra

Cátedra de Estudos Sefarditas "Alberto

Benveniste" da Faculdade de Letras da Universidade de Lisboa 


\section{HUMANISMO E CIÊNCIA}

\section{Antiguidade e Renascimento}

ANTÓNIO MANUEL LOPES ANDRADE

CARLOS DE MIGUEL MORA

JOÃO MANUEL NUNES TORRÃO

(COORDS.)

AVEIRO • COIMBRA • SÃO PAULO

2015

UA EDITORA • UNIVERSIDADE DE AVEIRO

IMPRENSA DA UNIVERSIDADE DE COIMBRA

ANNABLUME 


\section{HUMANISMO E CIÊNCIA: Antiguidade e Renascimento}

\author{
EDIÇÃO

UA EDITORA • UNIVERSIDADE DE AVEIRO
IMPRENSA DA UNIVERSIDADE DE COIMBRA
ANNABLUME

ORGANIZAÇÃO E COORDENAÇÃO EDITORIAL ANTÓNIO MANUEL LOPES ANDRADE

CARLOS DE MIGUEL MORA

JOÃO MANUEL NUNES TORRÃO

\author{
DESIGN DA CAPA \\ MEIOKILO DESIGN STUDIO
}

DESIGN

CARLOS COSTA

IMPRESSÃO E ACABAMENTO

SERSILITO • MAIA

ISBN

UA • 978-972-789-434-5

IUC • 978-989-26-0940-9

\section{ISBN DIGITAL}

UA • 978-972-789-435-2

IUC • 978-989-26-0941-6

DOI

http://dx.doi.org/10.14195/ 978-989-26-0941-6

DEPÓSITO LEGAL 368241/13

TIRAGEM 500 Exemplares

(C) 2015

UA EDITORA • UNIVERSIDADE DE AVEIRO IMPRENSA DA UNIVERSIDADE DE COIMBRA

ANNABLUME

\section{COMISSÃO CIENTÍFICA}

António Manuel Lopes Andrade

Carlos de Miguel Mora

Delfim Ferreira Leão

Henrique Leitão

João Manuel Nunes Torrão

Maria de Fátima Reis

Maria do Céu Zambujo Fialho

Miguel Ángel González Manjarrés

\section{TEXTOS}

Adelino Cardoso

Ana Leonor Pereira

Ana Margarida Borges

António Guimarães Pinto

António Maria Martins Melo

Bernardo Mota

Carlos A. Martins de Jesus

Carlos de Miguel Mora

Cristina Santos Pinheiro

Donald Beecher

Emília Oliveira

Isabel Malaquias

James W. Nelson Novoa

Joana Mestre Costa

João Manuel Nunes Torrão

João Rui Pita

Jorge Paiva

José Sílvio Moreira Fernandes

Maria de Fátima Silva

Miguel Ángel González Manjarrés

Rui Manuel Loureiro

Telmo Corujo dos Reis

Teresa Nobre de Carvalho

Vinicije B. Lupis

Virgínia Soares Pereira 


\section{HUMANISMO E CIÊNCIA}

\section{Antiguidade e Renascimento}

ANTÓNIO MANUEL LOPES ANDRADE

CARLOS DE MIGUEL MORA

JOÃO MANUEL NUNES TORRÃO

(COORDS.)

AVEIRO • COIMBRA • SÃO PAULO

2015

UA EDITORA • UNIVERSIDADE DE AVEIRO

IMPRENSA DA UNIVERSIDADE DE COIMBRA

ANNABLUME 
OBRA PUBLICADA

COM A COORDENAÇÃO

CIENTÍFICA DE:

CENTRO DE LÍNGUAS,

LITERATURAS E CULTURAS DA

UNIVERSIDADE DE AVEIRO

CENTRO DE ESTUDOS

CLÁSSICOS E HUMANÍSTICOS DA

UNIVERSIDADE DE COIMBRA

CÁTEDRA DE ESTUDOS SEFARDITAS

"ALBERTO BENVENISTE"

DA FACULDADE DE LETRAS DA

UNIVERSIDADE DE LISBOA 


\section{SUMÁRIO}

PREFÁCIO

1.1 "Teofrasto, Tratado das plantas. No alvor de uma nova ciência" 13

Maria de Fátima Silva

1.2 "Francisco de Melo e os fragmentos de teoria óptica de Pierre Brissot" 21 Bernardo Mota

1.3 "Algumas reflexões sobre as pedras preciosas nos Colóquios dos simples de Garcia de Orta" 37 Rui Manuel Loureiro

1.4 "Estratégias, patronos e favores em Colóquios dos Simples de Garcia de Orta" 63 Teresa Nobre de Carvalho

1.5 "As plantas na obra poética de Camões (épica e lírica)" 95 Jorge Paiva

1.6 "Nicolás Monardes, John Frampton and the Medical Wonders of the New World" .141 Donald Beecher

1.7 "Literatura e Medicina: alguns textos de Justo Lípsio e de dois doutores Luís Nunes" 161 António Guimarães Pinto

1.8 "Ontologias e idiossincrasias dos Amantes, à luz da Archipathologia de Filipe Montalto" ...... 211 Joana Mestre Costa \& Adelino Cardoso

1.9 "Gabriel da Fonseca. A New Christian doctor in Bernini's Rome". .227 James W. Nelson Novoa 


\section{2) DIOSCÓRIDES E O HUMANISMO PORTUGUÊS: OS COMENTÁRIOS DE AMATO LUSITANO}

2.1 "Léxico científico português nos Comentários de Amato: antecedentes e receção"

Ana Margarida Borges

2.2 "Usos medicinais das plantas, em Amato Lusitano: o bálsamo"

António Maria Martins Melo

2.3 "Amato Lusitano e a importância da ilustração botânica no século xVI.

Em torno das edições lionesas das Enarrationes (1558)"

Carlos A. Martins de Jesus

2.4 "Sobre la identificación entre ébano y guayaco en una entrada

del Index Dioscoridis de Amato Lusitano".

Carlos de Miguel Mora

2.5 "Os partos distócicos em Amato Lusitano e em Rodrigo de Castro:

fontes, doutrinas e terapias greco-romanas"

\section{Cristina Santos Pinheiro}

2.6 "Do carvalho ao castanheiro: usos e propriedades medicinais

de fagáceas nas Enarrationes de Amato Lusitano".

Emília Oliveira

2.7 "O mundo mineral nos Comentários a Dioscórides de Amato Lusitano".

Isabel Malaquias \& Virgínia Soares Pereira

2.8 "Alguns comentários de Amato: entre a estranheza e a realidade"

João Manuel Nunes Torrão

2.9 "Caracterização e usos terapêuticos de produtos de origem marinha

nos Comentários de Amato Lusitano a Dioscórides"

José Sílvio Moreira Fernandes

2.10 "La mandrágora de Amato Lusitano: edición, traducción y anotación"

Miguel Ángel González Manjarrés

2.11 "O vinho e os vinhos - usos e virtudes de um dom dos deuses

nas Enarrationes de Amato Lusitano"

Telmo Corujo dos Reis

2.12 "Amatus Lusitanus e Didaco Pirro: due ebrei portoghesi

e cerchia umanistica di Dubrovnik" 481

Vinicije B. Lupis

2.13 "Estudos contemporâneos sobre Amato Lusitano". 513

João Rui Pita \& Ana Leonor Pereira 


\section{O vinho e os vinhos - usos e virtudes de um dom dos deuses nas Enarrationes de Amato Lusitano ${ }^{1}$}

TELMO CORUJO DOS REIS 2

\section{RESUMO:}

O livro quinto das Enarrationes de Amato Lusitano abre com uma série de comentários consagrados à videira e à videira silvestre, ao fruto da videira (a uva e a uva passa) e ao vinho de uva (5.1-4 e 7), aos quais se seguem numerosos comentários consagrados a uma extensa variedade de outros vinhos (5.8, 9 e 19-42). 0 presente texto propõe-se explorar as qualidades terapêuticas do vinho, bem como os usos e virtudes medicinais (e ainda outros aspectos não menos curiosos) de muitos outros vinhos na obra de Amato Lusitano.

\section{PALAVRAS-CHAVE:}

Amato Lusitano; Dioscórides; vinho; medicina.

\section{ABSTRACT:}

The fifth book of the Enarrationes of Amato Lusitano opens with a series of reviews devoted to vine and the wild vine, the fruit of the vine (grape and raisin) and the wine of grapes (5.1-4 and 7 ) to which follow numerous reviews devoted to an extensive variety of other wines (5.8, 9 and 1942). This text aims to explore the therapeutic qualities of the wine of grapes, as well as the uses and medicinal properties (and other no less curious aspects) of many other wines in the work of Amato Lusitano.

\section{KEYWORDS:}

Amato Lusitano; Dioscorides; wine; medicine.

1 Este trabalho foi desenvolvido no âmbito do projecto de I\&D "Dioscórides e o Humanismo Português: os Comentários de Amato Lusitano" (http://amatolusitano.web.ua.pt) do Centro de Línguas, Literaturas e Culturas da Universidade de Aveiro, financiado por Fundos FEDER através do Programa Operacional Factores de Competitividade - COMPETE e por Fundos Nacionais através da FCT - Fundação para a Ciência e a Tecnologia, no âmbito do projecto FCOMP-01-0124-FEDER-009102.

2 Universidade da Madeira; Centro de Estudos Clássicos da Faculdade de Letras da Universidade de Lisboa: treis@uma.pt. 


\section{INTRODUÇÃO}

Conhecido desde a mais remota Antiguidade pelas suas numerosas qualidades e aplicaçóes terapêuticas, a ponto de um médico como Asclepíades, no séc. I. a. C., fazer uso do vinho, criteriosamente ministrado, como remédio contra todas as enfermidades, conforme refere Plínio-o-Velho ${ }^{3}$, o vinho não podia deixar de ocupar lugar de relevo na obra de um tratadista antigo como Dioscórides de Anazarbo. Dele, por conseguinte, e das suas muitas combinaçóes se ocupam as entradas com que se inicia o livro V do seu De materia medica.

Ao ocupar-se, nas Enarrationes, da obra do médico de Anazarbo, Amato Lusitano passa em revista cada uma das suas entradas, proporcionando ao leitor interessado um bom retrato dos seus conhecimentos sobre a matéria em questão, ao mesmo tempo que dá a conhecer usos que hoje nos parecem estranhos, exóticos ou, no mínimo, curiosos.

\section{A ENARRATIO N. ${ }^{\circ}$ 7, DE VINO}

\subsection{Abertura da Enarratio}

Ao vinho propriamente dito consagra Amato Lusitano a enarratio sétima do Livro V. Trata-se de um comentário extenso que ocupa, na edição de Veneza, de 1553, quase duas páginas (471-472). O texto principia com uma apresentação do vinho feita nos seguintes termos:

Vinum ubique suas habet laudes, quod odore, sapore, colore, dignoscitur. Et ut Erasmus Roterodamus, olim viva voce superaddebat, fama: bonum enim et generosum vinum suspensa hedera non habet opus, quod contra cicutam et alia frigida venena, meracum ac potens, praestantissimum antidotum est, ut olim Angelus Politianus ad medicorum mentem exacte exposuit. ${ }^{4}$

Por toda a parte encontra os seus louvores o vinho, que se distingue pelo aroma, pelo paladar e pela cor e ainda, como outrora Erasmo de Roterdáo de viva voz acrescentava, pela fama! Realmente, o vinho bom e generoso não há mister de hera dependurada, porque, puro e forte, é um antídoto muito eficaz contra a cicuta e outros venenos frios, como outrora Ângelo Poliziano expôs, exactamente segundo o pensamento dos médicos.

3 N. H. 23.32 e 26.14.

4 Enarrationes, 1553, p. 471. 


\subsection{Vinhos fortes e fracos, vinhos novos e velhos}

O texto prossegue, mas nele, ao invés do que seria de esperar, Amato não distingue o vinho tinto do vinho branco, nem procede a outras distinções que hoje se costumam fazer. Náo obstante, ocupa-se de dois aspectos ainda agora considerados da máxima relevância, por um lado o teor alcoólico do vinho, por outro a sua idade e durabilidade.

Quanto ao teor alcoólico do vinho, Amato não se lhe refere em termos de grau, como se faz na actualidade, mas recorre a um conjunto de adjectivos gregos e aos seus exactos correspondentes latinos: assim, ao vinho de alto teor alcoólico Amato chama oenodes e polýphorum, adjectivos gregos a que correspondem os latinos uinosum e multiferum, acrescentando: «isto é, [o vinho] que tolera [em mistura] muita água» («id est multam ferens aquam»). Já o vinho fraco (debile) é qualificado como oligophorum, vocábulo a que corresponde o adjectivo latino pauciferum, especificando que os vinhos desta qualidade: «não suportam em diluição água nenhuma» («nullam in diluitionem aquam ferentibus»).

Intimamente associada ao teor alcoólico dos vinhos está a sua capacidade para resistir à passagem do tempo, melhorando até, em certos casos, as suas qualidades. Deste mesmo aspecto se ocupa Amato Lusitano, comentando o texto de Dioscórides e reforçando a sua autoridade com o parecer de Galeno. Assim, os vinhos velhos serão aqueles «que ultrapassam os quinze ou os vinte anos de idade» («quae quindecim vel viginti excedunt aetatis annos»); os vinhos de meia-idade, para Dioscórides, terão entre sete e dez anos e, para Galeno, estarão entre os cinco e os dez anos. E Amato Lusitano conclui com um dado da sua experiência pessoal:

Cuius axioma, non sic superficie tenus ab omnibus intelligatur, velim, cum illud veritatem teneat in vinis potentissimis, et diu perdurantibus, qualia Hispaniarum sunt, quae ad triginta et quadraginta annos, perdurant, et vires suas potentissimas, ac valentissimas servant, veluti duo illa vina, quae nobis magnificus Antonius Musa Brasavola gustanda dedit, e cellario sive cella vinaria, illustrissimi ducis Herculis Estensis, quorum alterum centum quinquaginta annorum erat, alterum vero ducentorum. ${ }^{5}$

Gostaria que a sua afirmação [(de Galeno)] não fosse por todos compreendida assim superficialmente, visto que ela se mantém verdadeira nos vinhos mais fortes e mais duradouros, tais como são os das Espanhas, os quais perduram até aos trinta e aos quarenta anos e conservam as suas forças muito eficazes e muito válidas, como aqueles dois vinhos que nos deu a provar o magnífico António Musa Brasavola, da despensa ou adega do

5 Enarrationes, 1553, p. 471. 
ilustríssimo Duque Hércules de Este, dos quais um tinha cento e cinquenta anos, já o outro tinha duzentos.

A propósito dos vinhos fortes, lembra Amato um preceito de Hipócrates segundo o qual ele deve ser bebido depois da ingestão de melóes e outros frutos frios, e cita:

Quicumque cibi aut flatum, aut aestum, aut morsum, aut repletionem, aut tormen faciunt, a talibus liberat vinum meracum insuper potatum.

Todos aqueles alimentos que produzem flatulência, ou ardor, ou azia, ou enfartamento, ou cólica, de tais efeitos os liberta o vinho puro bebido logo de seguida.

A este conselho opunham-se, naturalmente, os seguidores de Avicena e dos Árabes, que diziam ser preferível beber água após a ingestão de tais frutos. Note-se que aos Árabes era ritualmente interdito o consumo de vinho e outras substâncias psicotrópicas, interdição que, como adiante se verá, era por vezes habilmente contornada.

Novos ou velhos, fortes ou fracos, deve qualquer um precaver-se do seu consumo, conclui, em todo o caso, Amato Lusitano: apenas os vinhos velhos poderão ser consumidos em segurança, desde que diluídos,

nova vero et recentia, corpus inflant, aegre concoquuntur, ac gravia et tumultuosa faciunt insomnia

já os novos e recentes incham o corpo e são difíceis de digerir e provocam insónias graves e tumultuosas.

E termina o passo com o seguinte conselho:

Nec est quod aliquis mihi obiiciat, Teuthonas, et inferiores omnes Germanos, assuetos potu vini novi, et recentis, mulsi dicti, esse, cum illi non sine noxa, et corporum suorum iactura, vinum illud Rhenense recens ebibant, facillime enim a quovis morbo moriuntur, nec ad senectutem, eorum ullus immunis aut sanus pervenit, quod millies illis obieci, Hispanos nostros, et Italos aliosque exteros mercatores, cum quibus Anthuerpiae magnam contrahunt familiaritatem, a tali usu praecavendo. ${ }^{6}$

6 Enarrationes, 1553, p. 472. 
E não há motivo para que alguém me lance a objecção de que os Teutôes e todos os da Germânia Inferior foram acostumados a beber o vinho novo e recente, chamado mosto, visto que eles bebem aquele vinho do Reno não sem dano e prejuízo dos seus corpos. Realmente, eles morrem com grande facilidade e de qualquer doença, e nenhum chega à velhice imune e são. Por isso, muitíssimas vezes lhes lancei a objecção de que os nossos Hispanos e os Italianos e outros mercadores estrangeiros, com quem eles contraem, em Antuérpia, grande familiaridade, se devem precaver de tal costume.

\subsection{0 vinho de Creta, antepassado do vinho Madeira}

A Enarratio sétima prossegue com uma caracterização do vinho de Creta, a que então se chamava, tal como ainda hoje, malvasia. Amato Lusitano caracteriza-o como potens, et generosum (ou seja, 'potente e generoso'), esclarecendo que era inicialmente designado pelo nome da ilha mediterrânica de onde era originário e celebrando as suas qualidades digestivas, pois stomachum dissolutum reficit, et vires amissas facile recuperat ('repara o estômago indolente e facilmente restabelece as forças perdidas').

Impóe-se, neste ponto, uma consideração relativamente ao celebrado vinho Madeira. É também ele um excelente digestivo e deverá corresponder, pelo menos em parte, ao vinum Cretense de Amato. Efectivamente sabe-se que o Infante D. Henrique, aquando do início da colonização do arquipélago da Madeira, mandou trazer cepas de várias ilhas do Mediterrâneo, a fim de apurar da possibilidade do seu cultivo ${ }^{7}$. Graça Melim, em monografia consagrada ao vinho Madeira, chega mesmo a afirmar que "A vinha, originária de Cândia ou Heraklion, capital da Ilha de Creta, entrou na Madeira por ordem do Infante D. Henrique, em 1445, vinte e seis anos após a sua descoberta" ${ }^{\text {. }}$

Já por meados do século xv, Cadamosto ficou maravilhado com os vinhos da região, deixando registado que na Ilha havia: "vinhos muitíssimo bons, e se se considerar que é habitada há pouco tempo, são em tanta quantidade, que chegam para os da ilha e se exportam muitos deles" .

A extrema generosidade do solo insular, então ainda fertilizado pelas cinzas recentes da sua floresta primordial, contribuiu para que a qualidade deste vinho fosse excepcionalmente boa, possibilitando igualmente a sua produção numa quantidade tal que permitia a sua exportação.

7 Rui CARITA, História da Madeira (1420-1566) - Povoamento e Produção Açucareira. Funchal, Secretaria Regional da Educação, 1989, p. 108.

8 Graça Melım, O Vinho das Ilhas. Funchal, O Liberal - Empresas de Artes Gráficas, 2000, p. 17.

9 Luís de CAdamosto, Viagem de Luís de Cadamosto e Pedro de Sintra (prefácio e notas históricas pelo Prof. Damião Peres). Lisboa, 1948, apud R. CARITA, História da Madeira..., op. cit., p. 108. 
Do seu renome, cedo alcançado, dá testemunho Shakespeare que, na peça Henrique IV, apresenta Falstaff a ser censurado, por Poins, pelo facto de ter vendido a sua alma ao diabo por um copo de vinho Madeira e uma perna de capão frio. A lenda inglesa fixou igualmente que o Duque de Clarence, ao ser condenado à morte após a sua derrota na Guerra das duas Rosas, escolhe morrer afogado num tonel de Malvasia ${ }^{10}$.

\title{
2.4. 0 vinho Albano
}

A Enarratio sétima termina com um apontamento sobre aquele que, no tempo de Amato Lusitano, entre os naturais de Ferrara, era chamado "vinho albano", um vinho branco de cor e frio por natureza, que refrescava até com maior eficácia do que a água, razão pela qual se revelava de extrema utilidade no tratamento dos doentes febris:

\begin{abstract}
At Albanum, non quod equidem putem Antiquorum, sed sic apud Ferrarienses nominatum vinum, colore album, natura frigidum, quod (mea sententia) potentius quam aqua infrigidat; nam aqua suis qualitatibus tantum infrigidat; Albanum vero vinum sua substantia, et praeter hoc, austeritate quadam, quod vinum Galenus intelligit, cum vinum continuo febricitantibus concedat, ut Centuriis curationum nostratum abunde diximus, ad quem locum lectorem relegamus, ut cetera quae de vino desiderantur, ibi legat. ${ }^{11}$
\end{abstract}

O vinho albano, não seguramente porque eu o considere o vinho dos Antigos, mas por ser assim designado entre os naturais de Ferrara, é branco de cor, de natureza frio, pelo que, em minha opiniâo, refrigera mais eficazmente do que a água: na verdade, a água refrigera apenas pelas suas qualidades, mas o vinho albano fá-lo pela sua própria substância e, além disto, por um certo travo acre. Galeno reconhece este vinho pois que de contínuo o administra aos doentes febris, como nós abundantemente dissemos nas Centúrias das nossas curas, para o qual lugar remetemos o leitor, para que aí leia tudo o mais que acerca do vinho se deseja.

10 R. CARITA, História da Madeira..., op. cit., pp. 108-109.

11 Enarrationes, 1553, p. 472. 


\title{
3. AS ENARRATIONES PRECEDENTES
}

Antes de se ocupar do vinho propriamente dito, já Amato Lusitano tratara, nas Enarrationes precedentes, da videira e da videira silvestre (1 e 2); da uva e da uva passa (3 e 4) e ainda da flor da videira e do sumo de agrazes (5 e 6).

\subsection{A videira}

\subsubsection{A combinação das tradições greco-romana e judaico-cristã}

No primeiro destes comentários, consagrado à videira, Amato Lusitano combina duas tradiçóes distintas, a greco-romana e a judaico-cristá, ao abrir o livro quinto com as seguintes palavras:

\begin{abstract}
Vitis planta, Baccho, sive Libero, Noe patri dicto dicata, ubique vulgatissima est, ex qua uvae pendent, et ex illis divinus ille liquor, vinum dictum, paratur

A videira, consagrada a Baco ou a Líber, chamado pai Noé [sic], é uma planta muito comum por toda a parte. Dela pendem os cachos de uvas e deles prepara-se aquele divino líquido chamado vinho.
\end{abstract}

Ora, na tradição pagã, Baco, ou Dioniso, filho de Zeus e de Sémele, é considerado o descobridor da videira e o inventor do vinho. Este deus, em Roma, veio a identificar-se com Liber Pater, uma antiga divindade itálica ${ }^{12}$. Já na tradição judaico-cristã, a descoberta da videira e a consequente invenção do vinho são atribuídas a Noé, como se depreende das seguintes palavras:

Noé foi agricultor e o primeiro a cultivar a vinha. Certa ocasião bebeu vinho, ficou bêbedo e despiu-se completamente dentro da sua tenda. Cam, pai de Canaã, viu o seu pai nu e foi contar o caso aos seus dois irmãos, que estavam fora da tenda. Mas Sem e Jafet pegaram numa peça de roupa, e levantando-a por sobre os ombros, aproximaram-se do pai, caminhando de costas viradas para ele. Assim cobriram o pai, estando sempre de costas para ele, para o não verem nu. ${ }^{13}$

12 Pierre Grimal, Dicionário da Mitologia Grega e Romana. Lisboa, DIFEL - Difusão Editorial, 1992, pp. 121-122.

13 Génesis, 9.20.23. Bíblia Sagrada - A Boa Nova, tradução interconfessional do hebraico, do aramaico e do grego em português corrente. Lisboa, Difusora Bíblica, 1995. 
Ainda que o texto sagrado o não afirme explicitamente, pode deduzir-se que, tendo sido o primeiro a cultivar a vinha, foi também Noé o inventor do vinho. Amato Lusitano opta, portanto, por uma via intermédia que concilia as duas tradições, identificando Noé com Dioniso (ou Líber).

\subsubsection{Caracterização da videira e aplicações terapêuticas}

Sobre a videira propriamente dita, Amato afirma ser um alimento frio: os seus rebentos, frescos, acalmam a azia; a seiva que goteja do tronco de uma videira podada, ainda líquida ou já sob a forma de resina, é um bom diurético, além de tornar as faces mais belas; o sarmento, uma vez seco e posto em brasa, usa-se, como um cautério, para extirpar as verrugas; as cinzas resultantes da sua combustão, combinadas com as do tamarisco, usam-se em unguentos praecipue ad morbum Gallicum (ou seja, 'principalmente para a sífilis').

\subsection{As uvas e as uvas passas}

Quanto às uvas, Amato Lusitano adverte para os perigos da sua ingestão logo após serem colhidas, quando ainda estáo saturadas de orvalho, uma vez que perturbam o funcionamento do aparelho digestivo. Quando, porém, essa excessiva humidade desaparece, transformam-se num excelente alimento, acabando por obter a primeira categoria entre os frutos secos, logo seguidas dos figos.

As uvas passas, de que Amato Lusitano se ocupa na Enarratio quarta, são excelentes para as afecções do peito e do fígado, devendo contudo evitar-se a ingestão das suas grainhas, pelo seu efeito excessivamente adstringente. Efectivamente as grainhas pectus constringunt, et obstructiones parant ('constringem o peito e dão origem a obstruçóes.')

Que os doentes devem abster-se a todo o custo de as comer afirmam-no várias autoridades alegadas por Amato, tais como Galeno, Alexandre de Trales, Aécio e ainda Avicena. Excelentes serão, por conseguinte, as passas de uva que já são, por natureza, desprovidas de grainhas, como aquela a que Amato Lusitano chama uva passa de Corinto. Esta ieiuno stomacho sumpta, prius aqua vel vino mersa, trium unciarum pondere, alvum movet, et purgat ('sendo comida com o estômago em jejum, previamente demolhada em água ou em vinho, com o peso de três onças, move e purga o ventre').

As grainhas têm, não obstante, a virtude de fortalecer o estômago, pelo que Amato adverte que a uva passa pode ser comida antes da refeição sem a grainha, se o objectivo terapêutico for purgar o ventre, ou com a grainha, se o objectivo for robustecer o estômago. Sendo tomada após a refeição deverá ser ingerida inteira, pois acumula ambas as funções. 


\title{
3.3. A flor da videira e o sumo de agrazes
}

Nas Enarrationes 5 e 6 referem-se as virtudes da flor da videira e do sumo de agrazes, respectivamente. Da primeira escreve Amato que é

\begin{abstract}
sua natura, constringentem, stomacho conductibilem; qua de causa, inter medicamenta stomachica persaepe miscemus

adstringente pela sua natureza, conveniente ao estômago, motivo pelo qual muitas vezes a misturamos com os medicamentos estomacais.
\end{abstract}

Já sobre o sumo de agrazes, isto é, sobre o sumo obtido a partir de uvas ainda não amadurecidas, escreve Amato que é útil contra as nebulosidades da vista e a lepra e ainda, se não for excessivamente salgado, para os doentes com febre. Se for excessivamente salgado, subverte-se o seu efeito antipirético e acentuam-se as suas qualidades dessecativas, fazendo, assim, aumentar as febres e deixando o corpo mais seco do que o conveniente.

\section{OS OUTROS VINHOS}

\subsection{Alguns vinhos caídos em desuso}

Depois de, na Enarratio sétima, se ocupar demoradamente do vinho propriamente dito, Amato Lusitano apresenta uma extensa série de outros vinhos, que são apenas objecto de um brevíssimo comentário.

Sobre muitos deles a única informação veiculada é que, no tempo de Amato Lusitano, já não se preparavam. De um modo geral, Amato escreve: Hodie non paratur: parari tamen posset facillime (ou seja: 'Não se prepara na actualidade, poderia, contudo, preparar-se muito facilmente'», Enarratio 19) ou Non paratur, sed paucis expensis parari possit (ou seja: 'Não se prepara, mas poderia preparar-se com pouca despesa', Enarratio 22) ou simplesmente Non paratur (ou seja: 'Não se prepara', Enarratio 25). Está nesta situação o vinho de mosto com mel e, muito semelhante a este, o vinho adoçado com mel, o vinho de esquila (cebola-do-mar ou cebola-albarrã), os vinhos preparados com a água do mar, o vinho de marmelos, o vinho de flor de videira silvestre, o vinho de bagas de murta, o vinho de lentisco e de terebinto e o vinho de hissopo (respectivamente Enarrationes 8, 9, $19,20,22,25,28,29,30$ e 38$)$. 


\subsection{Sobre os processos de produção}

Note-se que alguns destes vinhos correspondem, por certo, a preparados obtidos a partir de vinho de uva, devidamente condimentado com outras substâncias, usando-se para suporte destas o álcool resultante do processo de fermentação natural do vinho. Que este uso era habitual entre os antigos Gregos afirma-o Graça Melim, ao referir que eles:

Introduziram também métodos para combater a acidez do vinho e para a preparação de medicamentos feitos à base de uma mistura deste néctar com certas frutas.

E acrescenta que:

Os vinhos, na antiga Grécia, eram também empregues na confecção de molhos, unguentos e cosméticos ${ }^{14}$.

Por outro lado, este modo de preparar os vinhos depreende-se de algumas palavras de Amato Lusitano, por exemplo, num parágrafo como a Enarratio 27, consagrada ao vinho de rosas:

Ex vino, et rosis, balaustiis, et pomis cupressi, ac rosmarino, adiectis aliis constringentibus, ut myrto, galla, summitatibus rubi, lentisco, absinthio, ac aliis similibus, vinum roborans membra debilia et ulceribus affecta, quotidie paratur. ${ }^{15}$

A partir de vinho e de rosas, de flores da romá selvagem e de frutos de cipreste e de alecrim, acrescentados outros adstringentes, como a baga da murta, a noz de gralha e as pontas da amora brava, o lentisco, o absíntio e outros semelhantes, quotidianamente se prepara um vinho que robustece os membros enfraquecidos e afectados por úlceras.

Para idêntica conclusão apontam as palavras do título a que correspondem os números 34, 35 e 36: De vino ex pineis nucibus condito. De vino ex cedro, ac aliis fructibus confecto. De vino picato ('Sobre o vinho temperado com pinhóes; sobre o vinho preparado a partir do cedro e de outros frutos; sobre o vinho aromatizado com pez).

Que o vinho de uva era utilizado como suporte de outras substâncias afirma-o Amato Lusitano, por exemplo, na cura XXXIV das suas Centúrias de Curas Medicinais (quinta centúria), «sobre a aceleração de um parto»:

14 G. Melim, O Vinho das Ilhas..., op. cit., p. 8.

15 Enarrationes, 1553, p. 476. 
R. Cinnamomi optimi, trochiscorum de myrrha, croci optimi ana drachmam mediam: omnia optime, et subtiliter triturentur: et generoso vino excepta, bibenda propinentur. ${ }^{16}$

R. de cinamomo muito bom, de trociscos de mirra, de croco muito bom, ana, meia dracma. Triture-se tudo muito bem e muito fino. Feito um excipiente com vinho generoso, dê-se-lhe a beber.

A propósito deste tópico registe-se o conteúdo da Enarratio 41, a penúltima da série, 'Sobre os vinhos preparados com numerosas e variadas especiarias', que afirma apenas que Multa huiusmodi vina parturientes mulieres praeparant ('As mulheres em trabalho de parto preparam muitos vinhos deste género'). O hábito de ministrar às parturientes um cálice de vinho do Porto (quando não mais!), prevaleceu, em Portugal, pelo menos até ao terceiro quartel do século xx...

A razão do uso do vinho de uva para suporte destas substâncias poder-se-á explicar em função de algumas observações do próprio Amato na já referida Enarratio sétima. Assim, usarse-ia vinho de uva em vez de água, visto esta ser fria por natureza (e o vinho albano, como já vimos, ainda mais frio); os vinhos em geral seriam quentes e, como tal, mostravam-se eficazes no tratamento de afecçóes frias, sendo, como também vimos, antídotos eficazes precisamente contra venenos frios, como, por exemplo, a cicuta. O uso medicinal do vinho, uma substância quente por natureza, seria particularmente conveniente no caso de o paciente ser uma mulher, uma vez que contrabalançava a natureza excessivamente fria e húmida desta, conforme ensinava a doutrina hipocrática dos humores.

Outros vinhos referidos poder-se-iam obter por recurso a outros processos, nomeadamente mergulhando frutos muito doces e secos em água e acrescentando, depois, algum fermento de vinho, por forma a induzir artificialmente a fermentação do açúcar, processo do qual resulta a sua transformação em álcool.

Poderá ser esse o processo de fabrico do vinho de tâmaras, descrito na Enarratio 31 ou do vinho produzido a partir de passas de figo, objecto de comentário em 32-33. Sobre o primeiro deles, escreve Amato que é utilizado como bebida pelos Indianos e que os Turcos (Turcae): ex dactylis, et passis uvis aliisque rebus, potum parant, quod vini vice accipiunt, et eo non raro inebriantur ('preparam uma beberagem a partir de tâmaras e uvas passas e outras substâncias, a qual admitem em lugar do vinho, e com ela não raras vezes se embriagam’). Os Turcos teriam, assim, encontrado uma forma de contornar a interdição do consumo de álcool — entenda-se

16 Amato Lusitano, Centuriae Duae - Quinta et Sexta. Lugduni, apud Gulielmum Rouillium, 1564. Reproduz-se a tradução das Centúrias de Curas Medicinais, vol. III, p. 224, da autoria de Firmino CRESPO, a quem se deve, aliás, a tradução integral da obra do médico albicastrense. 
vinho - a que estavam sujeitos enquanto seguidores da religião islâmica. Note-se que o conteúdo desta Enarratio poderá, pelo menos em parte, resultar da observação directa de Amato Lusitano.

Sobre o segundo destes vinhos, registe-se que ainda hoje é produzido desse modo, a partir não de passas de figo, mas de uva, por exemplo, na Escandinávia, o que acaba por corresponder às palavras do Albicastrense, que afirma que tal vinho era produzido regionibus frigidis (ou seja, 'nas regiōes frias').

\subsection{Alguns outros vinhos}

Alguns outros vinhos referidos por Amato Lusitano são, por exemplo, o vinho de marmelos com mel (Enarratio 21), que pode ser temperado com mel ou com açúcar; o vinho de agrazes com mel Enarratio 23), substituído por um xarope obtido a partir dos mesmos agrazes temperados com açúcar, com larga aplicação contra as febres terçãs; o vinho de peras (Enarratio 24), que ao tempo de Amato se preparava em França, em Espanha, bem como em outros lugares; e que poderá eventualmente corresponder à sidra; o vinho de romã (Enarratio 26), produzido a partir do sumo de romás ácidas e que era dado de beber aos doentes febris; ou ainda o vinho de absíntio, que Amato afirma ser produzido In universa Germania [...] praecipue Mechliniae prope Lovanium, ubi saepius illud pitissavimus ('por toda a Germânia [...] principalmente em Malines, perto de Lovaina, onde nós muitas vezes dele provámos', Enarratio 37). Note-se, uma vez mais, o teor autobiográfico destas palavras.

\subsection{Alguns vinhos desconhecidos dos Antigos}

Ao aproximar-se do termo da sua abordagem da matéria de Baco, Amato Lusitano não deixa de registar, numa única entrada (Enarratio 39), alguns vinhos que, no tempo em que escrevia, eram preparados com plantas que não eram conhecidas dos Antigos. Assim, o vinho preparado com euphragia era utilizado contra os males da vista; o vinho de sena mostrava-se útil para o tratamento das afecçóes motivadas pelo excesso de bílis negra (os atrabiliarios affectus); o vinho de guaiaco, o "pau da Índia», era usado no tratamento da sífilis; a paineira-vermelhada-índia, uma árvore de grande porte que lembra as sumaúmas, servia para preparar um vinho útil contra os defluxos e, finalmente, a salsaparrilha (em latim, salsa pirrilha) igualmente útil contra as sobreditas afecções. 


\section{CONCLUSÃO}

A conclusão da série de comentários consagrados por Amato Lusitano ao vinho e aos vinhos, com a qual concluímos também esta nossa abordagem, surge na Enarratio 42, De variis vinis ex variis herbis confectis ('Sobre vários vinhos, produzidos a partir de várias plantas'). Aí, sem se deter em nenhum vinho em concreto, Amato mostra compreender que, afinal, com a maior facilidade se podem fazer diferentes preparos à base de vinho, utilizando-o como suporte das mais variadas plantas, com os quais seria possível, quase à maneira de Asclepíades, curar o maior número de doenças. Esses vinhos, escreve Amato, rei medicae magnum afferrent ornamentum ('poderiam trazer uma grande glória à ciência médica') e o texto termina com uma nota que associa, de um modo paradoxal, inovação e tradição, uma vez que escreve que: Multa tamen hodie, ut audio parari incipunt ('Actualmente, contudo, muitos começam, segundo ouço dizer, a ser preparados'), acabando por remeter o leitor para a obra de Arnaldo de Vilanova, que é, afinal, uma autoridade medieval.

\section{BIBLIOGRAFIA:}

Amato Lusitano, Centuriae Duae - Quinta et Sexta. Lugduni, apud Gulielmum Rouillium, 1564.

Аmato Lusitano, Centúrias de Curas Medicinais. Volume I [-IV]. Prefácio e tradução Firmino Crespo.

Lisboa, Universidade Nova de Lisboa - Faculdade de Ciências Médicas, s/d [4 vols.].

Amato Lusitano, In Dioscoridis Anazarbei De Medica Materia Libros Quinque Enarrationes Eruditissimae.

Venetiis, apud Gualterum Scotum, 1553.

Bíblia Sagrada - A Boa Nova, tradução interconfessional do hebraico, do aramaico e do grego em português corrente. Lisboa, Difusora Bíblica, 1995.

Cadamosto, Luís de, Viagem de Luís de Cadamosto e Pedro de Sintra (prefácio e notas históricas pelo Prof. Damião Peres). Lisboa, 1948.

Carita, Rui, História da Madeira (1420-1566) - Povoamento e Produção Açucareira. Funchal, Secretaria Regional da Educação, 1989.

Grimal, Pierre, Dicionário da Mitologia Grega e Romana. Lisboa, DIFEL - Difusão Editorial, 1992.

Melim, Graça, O Vinho das Ilhas. Funchal, O Liberal - Empresas de Artes Gráficas, 2000. 
A partir dos alvores do século XVI, a matéria médica torna-se indiscutivelmente um tema de primeira grandeza entre os membros da República das Letras, objecto de estudo e de controvérsia entre os mais notáveis humanistas europeus, em particular entre os cultores da arte médica. Entre os autores em destaque neste volume encontram-se, à cabeça, os nomes de Amato Lusitano, Garcia de Orta e Nicolás Monardes, famosos pelos contributos valiosos que deram para o conhecimento do mundo natural. 0 volume encontra-se dividido em duas partes: a primeira, subordinada ao título "Humanismo e Ciência", alberga os estudos que versam sobre todos os autores estudados, à excepção de Amato Lusitano; a segunda está reservada a um conjunto de trabalhos dedicados exclusivamente ao médico albicastrense, cuja autoria se fica a dever, em boa parte, aos membros da equipa do projecto de I\&D "Dioscórides e o Humanismo Português: os Comentários de Amato Lusitano", tomando, por isso, 0 seu próprio título. Nesta segunda parte, oferece-se, desde já, aos leitores uma amostra significativa do trabalho desenvolvido no âmbito do projecto e que culminará, assim se espera, na edição e tradução integral para língua portuguesa das quatro obras previstas de Dioscórides, Amato Lusitano e Pietro Andrea Mattioli. 
